\title{
Prediction of whiteness index of cotton using bleaching process variables by fuzzy inference system
}

\author{
Abu Naser Md. Ahsanul Haque ${ }^{*^{*}}$ (D, Shamima Akter Smriti', Manwar Hussain², Nawshin Farzana1, \\ Fahmida Siddiqa ${ }^{1}$ and Md. Azharul Islam ${ }^{3}$
}

*Correspondence: anmahaque@gmail.com

${ }^{1}$ Department of Textile Engineering, Daffodil International University, Dhaka, Bangladesh

Full list of author information is available at the end of the article

\begin{abstract}
A fuzzy prediction model has been built based on hydrogen peroxide concentration, temperature and time of bleaching as the input variables and knitted fabric whiteness index as the output variable. The process parameters affecting the whiteness index of cotton knitted fabrics are very non-linear. Fuzzy inference system is a prospective modeling tool as it can map effectively in nonlinear domain with minimum investigational data. Triangular-shaped membership functions were considered for the variables and total 48 rules were created in this study. It was found that the sole effect of the concentration of hydrogen peroxide on whiteness is pretty low, but is affected by temperature noticeably even in a fixed concentration of hydrogen peroxide. The model proposed in the present study has been verified by additional experimental data set. The root mean square, mean absolute error percentage and coefficient of determination $\left(R^{2}\right)$ between the predicted and experimental values were found to be $0.536,0.798$ and 0.959 respectively. The results validate that the model can be applied suitably for the prediction of fabric whiteness index in textile industries.
\end{abstract}

Keywords: Whiteness index, Prediction, Fuzzy logic, Knitted fabric, Bleaching, Cotton

\section{Introduction}

Whiteness is an aspect of color resultant by high luminosity with an absence of any hue (Wyszecki and Stiles 1982; Steen and Dupont 2003; Choudhury 2006). A white plane reflects more than $50 \%$ light all over the visible spectrum. The whiter appearance of the substance depends on the uniformity of the spectral reflectance and percentages of light reflection (Akgun 2015). White is an achromatic color and characterized by constant absorption from 400 to $700 \mathrm{~nm}$ wave length (Zollinger 2003).

Cotton owns a natural color due to the protoplasmic residues of the protein as well as flavones pigments of cotton flowers (Abdel-Halim 2012). Therefore, it needs to be pretreated to produce a permanent white surface that is suitable for dyeing or any other wet process (Kabir et al. 2014). Hydrogen peroxide $\left(\mathrm{H}_{2} \mathrm{O}_{2}\right)$ is mostly used bleaching agent among all other, as it can bleach both cellulose and protein fibers successfully (Trotman 1975). This chemical is stable in acidic medium but bleaches with the addition of alkali. The per-hydroxyl ion $\left(\mathrm{HO}_{2}^{-}\right)$liberated in alkaline state, acts like a weak dibasic acid

(C) The Author(s) 2018. This article is distributed under the terms of the Creative Commons Attribution 4.0 International License (http://creativecommons.org/licenses/by/4.0/), which permits unrestricted use, distribution, and reproduction in any medium, provided you give appropriate credit to the original author(s) and the source, provide a link to the Creative Commons license, and indicate if changes were made. 
that is very unstable. The presence of oxidizable colored stuff in cotton promotes to the decomposition and bleaching takes place (Abdul and Narendra 2013).

The assessment of whiteness by instrument is usually performed by two-step operation; measurement of reflectance and evaluation of whiteness from data obtained. There are quite a few methods available in order to calculate whiteness quantitatively which took apart the dependence on visual estimations (Ganz 1979; Choudhury 2000; Jafari and Amirshahi 2008).

The CIE whiteness index (WI) under CIE1964 standard observer $\left(10^{\circ}\right)$ and D65 illuminant viewing conditions, can be represented by Eq. (1) (Jafari and Amirshahi 2008):

$$
W=Y+800(x n-x)+1700(y n-y)
$$

where, $Y$ is the lightness and $x, y$ and $x n, y n$ are chromaticity coordinates of the tested sample and the illuminant respectively. The CIE WI is controlled by Eq. (2) (Jafari and Amirshahi 2008):

$$
40<W<(5 Y-280)
$$

The validity of these equations in comparison to visual evaluations had already been reported by several researchers (Uchida 1998; Jafari and Amirshahi 2007, 2008).

Though bleaching is a significant part of cotton's pre-treatment and affects massively to the post-processes, there is no prediction model developed yet for whiteness index on basis of bleaching process parameters. In this context, an attempt done by Haque and Islam (2015) was to optimize the bleaching parameters for getting balance between bursting strength and whiteness index. Three non-linear parameters $\left(\mathrm{H}_{2} \mathrm{O}_{2}\right.$ concentration, process temperature and time duration) those have intra relations were found to be significant that affects whiteness index in a constant $\mathrm{pH}$ (Haque and Islam 2015). Thus, predictions of whiteness index hold the significance before the bleaching operation starts as the whiteness of the fabric can crucially affect dyeing process afterwards.

There are different prediction models like Artificial Neural Network (ANN) and Adaptive Neuroinference System (ANFIS) used frequently in textile domain over the years. But there is only one report available which proposed on the optimization of cotton pretreatment by prediction modeling through ANN, though it was more specifically on the bio-scouring of organic cotton (Vigneswaran et al. 2012). In fact, ANN and ANFIS models need lots of input-output data for optimization of model parameters which is not an easy task. Besides, they are time consuming and labour intensive as well (Jamshaid et al. 2013; Hossain et al. 2015). Moreover, ANN does not propose the core logic base on which the decisions can be made (Hatua et al. 2014).

In contrast, fuzzy inference system (FIS) is a quite capable modeling tool to overcome the limitations of ANN and ANFIS models as it is based on fuzzy logic and can simply convert the experience of experts to a set of inference system based rule and is focused on modes of reasoning which are approximate rather than exact. Fuzzy inference system is an extension of crisp logic derived from the fuzzy mathematical set theory proposed by Zadeh (1965) (Haghighat et al. 2014; Ngai et al. 2014; Vadood 2014). It is an artificial intelligence having a multi-valued logic structure and the implementation is easier than other models due to its ability to perform with a small amount of experimental data in non-linear, trial-error, ill-defined and complex textile domain. Furthermore, this system 


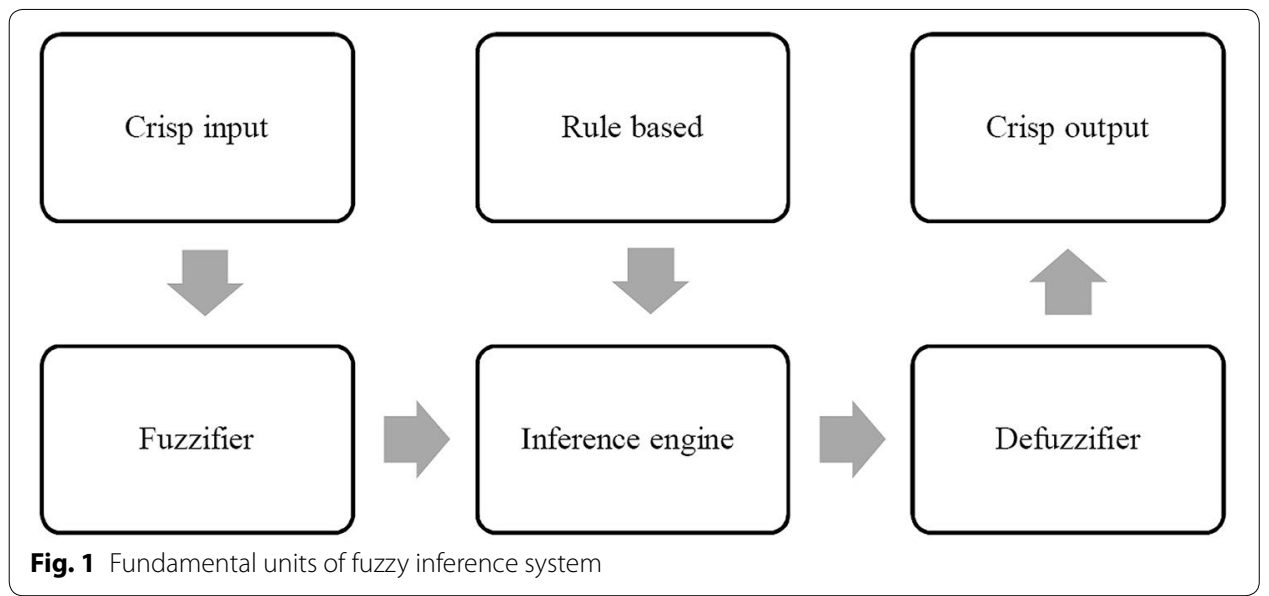

is cheaper and more reasonable in design cost and very simple in application (Majumdar and Ghosh 2008; Vadood 2014; Hossain et al. 2015, 2016). Fundamentally FIS contains four major modules (Gopal 2010; Hossain et al. 2014) which are shown in Fig. 1.

Fuzzy model has previously been applied successfully by several researches in textile. For instance, predicting yarn strength in spinning, predicting bursting strength, spirality, shrinkage, tactile sensory properties of knitted fabric, predicting fabric GSM, predicting color properties and predicting needle penetration force in denim fabric (Majumdar and Ghosh 2008; Jeguirim et al. 2011; Haghighat et al. 2014; Hossain et al. 2014, 2016, 2017; Shahid and Hossain 2015). However, there is no report on prediction of whiteness index of cotton fabric by varying different bleaching parameters which is taken into account in the current study.

\section{Methods}

\section{Fabric and chemicals}

Single jersey cotton knitted fabric of 130 GSM was considered for the study. Sodium Hydroxide $(\mathrm{NaOH})$ and Hydrogen peroxide $\left(\mathrm{H}_{2} \mathrm{O}_{2}\right)$ of commercial grade were used for the bleaching operations. Kappazon H53 peroxide stabilizer (Kapp-chemie, Bangladesh) was also used for $\mathrm{H}_{2} \mathrm{O}_{2}$ stabilizing action.

\section{Bleaching of fabric}

Bleaching operations of the samples were done in a Mathis Labomat lab dyeing machine. Fabrics were treated according to a set of values for Hydrogen peroxide concentration $(1.8-2.2 \mathrm{~g} / \mathrm{L})$, temperature $\left(78-108^{\circ} \mathrm{C}\right)$ and time $(20-50 \mathrm{~min})$. Sample weight was $12.5 \mathrm{~g}$ constant with a 1:10 Material liquor ratio (MLR). Concentrations of $\mathrm{NaOH}$ and Kappazon $\mathrm{H} 53$ were kept 2 and $1 \mathrm{~g} / \mathrm{L}$ constant respectively in each bleaching bath. The after treatment of the fabric samples was done by the following steps- 
Hot wash $\left(70^{\circ} \mathrm{C}\right)$

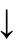

Cold wash $\left(27^{\circ} \mathrm{C}\right)$

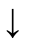

Squeezing (by hand)

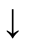

Drying $\left(70{ }^{\circ} \mathrm{C}, 30 \mathrm{~min}\right)$

A total of 40 bleached samples were collected for measuring whiteness index.

\section{Whiteness index (WI) measurement}

The beached fabrics were tested in a spectrophotometer (datacolor 650, USA) for determining the whiteness index in D65 illuminant and $10^{\circ}$ observer setting. The results are shown in Table 1.

\section{Development of fuzzy prediction model}

Three bleaching process variables- hydrogen peroxide concentration $(P C)$, temperature $(T)$ and time $(t)$ were used as input variables and whiteness index $(W I)$ of the bleached fabrics was used as the output variable for the development of the fuzzy prediction model. A fuzzy logic toolbox from MATLAB (version 7.10.0) was used to develop the proposed fuzzy prediction model of whiteness index. For fuzzification, the input variable $P C$ was specified by three possible linguistic fuzzy sets, namely low $(L)$, medium $(M)$ and high $(H)$. Four fuzzy numbers, T1, T2, T3 and T4 were used for the input variables of $T$ and for $t$, four fuzzy numbers $t 1, t 2, t 3$ and $t 4$ were considered. For the output variable WI, eight linguistic fuzzy sets, $L 1, L 2, L 3, L 4, L 5, L 6, L 7$ and $L 8$ were used. These linguistic fuzzy sets are able to cover appropriately the complete ranges of input and output variables for regular cotton bleaching process in industries. The linguistic fuzzy sets for input-output parameters are depicted in Table 2.

For this fuzzy prediction model, triangular-shaped membership functions were used for both input and output variables as it is the most precise among other all membership functions (Marakoğlu and Çarman 2010). The triangular formed membership functions for the fuzzy variables $P C, T, t$ and WI developed by MATLAB fuzzy toolbox are shown in Figs. 2, 3, 4, and 5. Following fuzzification, total 48 rules were created for the input and output variables based on expert knowledge and previous experience. A mamdani max-min inference approach was used to combine the fuzzy sets into a single fuzzy set. Finally, the centre of gravity defuzzification method was applied to convert the fuzzy output into non-fuzzy crisp numeric value by Eq. (3) below (Haghighat et al. 2014).

$$
z=\frac{\sum_{i=1}^{n}\left(\mu_{i} \times b_{i}\right)}{\sum_{i=1}^{n}\left(\mu_{i}\right)}
$$


Table 1 Experimental results of whiteness index

\begin{tabular}{|c|c|c|c|c|}
\hline \multirow[t]{2}{*}{ Trial number } & \multicolumn{3}{|c|}{ Input values } & \multirow{2}{*}{$\begin{array}{l}\text { Target value } \\
\text { WI }\end{array}$} \\
\hline & $P C(\mathrm{~g} / \mathrm{L})$ & $T\left({ }^{\circ} \mathrm{C}\right)$ & $t(\min )$ & \\
\hline 1 & 1.8 & 78 & 20 & 47.21 \\
\hline 2 & 1.8 & 78 & 40 & 58.65 \\
\hline 3 & 1.8 & 78 & 50 & 59.26 \\
\hline 4 & 1.8 & 83 & 30 & 58.01 \\
\hline 5 & 1.8 & 88 & 20 & 55.55 \\
\hline 6 & 1.8 & 88 & 40 & 61.25 \\
\hline 7 & 1.8 & 93 & 50 & 62.50 \\
\hline 8 & 1.8 & 98 & 20 & 58.65 \\
\hline 9 & 1.8 & 98 & 50 & 63.16 \\
\hline 10 & 1.8 & 103 & 20 & 58.76 \\
\hline 11 & 1.8 & 103 & 40 & 62.94 \\
\hline 12 & 1.8 & 108 & 40 & 63.04 \\
\hline 13 & 1.8 & 108 & 50 & 63.62 \\
\hline 14 & 2.0 & 78 & 20 & 47.76 \\
\hline 15 & 2.0 & 78 & 30 & 57.31 \\
\hline 16 & 2.0 & 78 & 40 & 59.64 \\
\hline 17 & 2.0 & 83 & 30 & 58.61 \\
\hline 18 & 2.0 & 83 & 40 & 59.96 \\
\hline 19 & 2.0 & 83 & 50 & 61.02 \\
\hline 20 & 2.0 & 88 & 40 & 61.84 \\
\hline 21 & 2.0 & 93 & 20 & 57.75 \\
\hline 22 & 2.0 & 98 & 20 & 59.16 \\
\hline 23 & 2.0 & 98 & 40 & 63.45 \\
\hline 24 & 2.0 & 98 & 50 & 63.86 \\
\hline 25 & 2.0 & 108 & 30 & 62.45 \\
\hline 26 & 2.0 & 108 & 40 & 63.51 \\
\hline 27 & 2.2 & 78 & 20 & 48.25 \\
\hline 28 & 2.2 & 78 & 40 & 59.64 \\
\hline 29 & 2.2 & 78 & 50 & 60.11 \\
\hline 30 & 2.2 & 88 & 30 & 60.54 \\
\hline 31 & 2.2 & 88 & 40 & 62.66 \\
\hline 32 & 2.2 & 88 & 50 & 62.73 \\
\hline 33 & 2.2 & 93 & 40 & 63.03 \\
\hline 34 & 2.2 & 93 & 50 & 63.65 \\
\hline 35 & 2.2 & 98 & 20 & 59.98 \\
\hline 36 & 2.2 & 98 & 30 & 62.53 \\
\hline 37 & 2.2 & 103 & 20 & 60.11 \\
\hline 38 & 2.2 & 103 & 30 & 62.84 \\
\hline 39 & 2.2 & 108 & 30 & 63.01 \\
\hline 40 & 2.2 & 108 & 50 & 64.65 \\
\hline
\end{tabular}


Table 2 Linguistic fuzzy sets for input-output parameters

\begin{tabular}{lll}
\hline Parameters & Range & Linguistic fuzzy sets \\
\hline Peroxide concentration, $P C(\mathrm{~g} / \mathrm{L})$ & $1.8-2.2$ & low $(L)$, medium $(M)$, high $(H)$ \\
Temperature, $T\left({ }^{\circ} \mathrm{C}\right)$ & $78-108$ & $T 1, T 2, T 3, T 4$ \\
Time, $t($ min $)$ & $20-50$ & $t 1, t 2, t 3, t 4$ \\
Whiteness index, $W I$ & $47-65$ & $L 1, L 2, L 3, L 4, L 5, L 6, L 7, L 8$
\end{tabular}

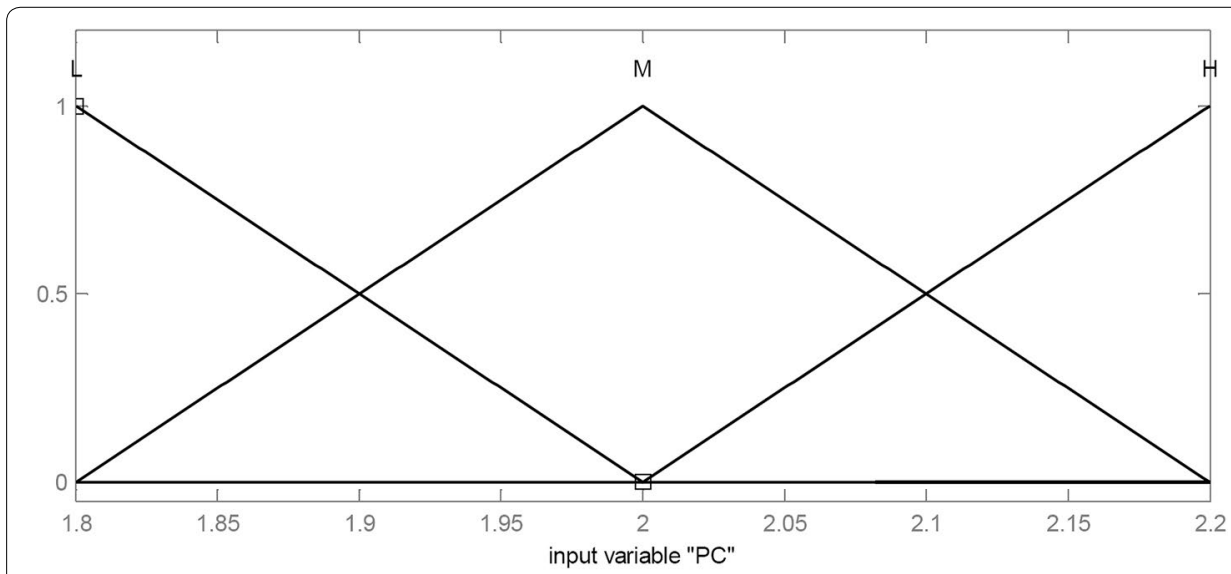

Fig. 2 Membership function of input variable " $P C$ "

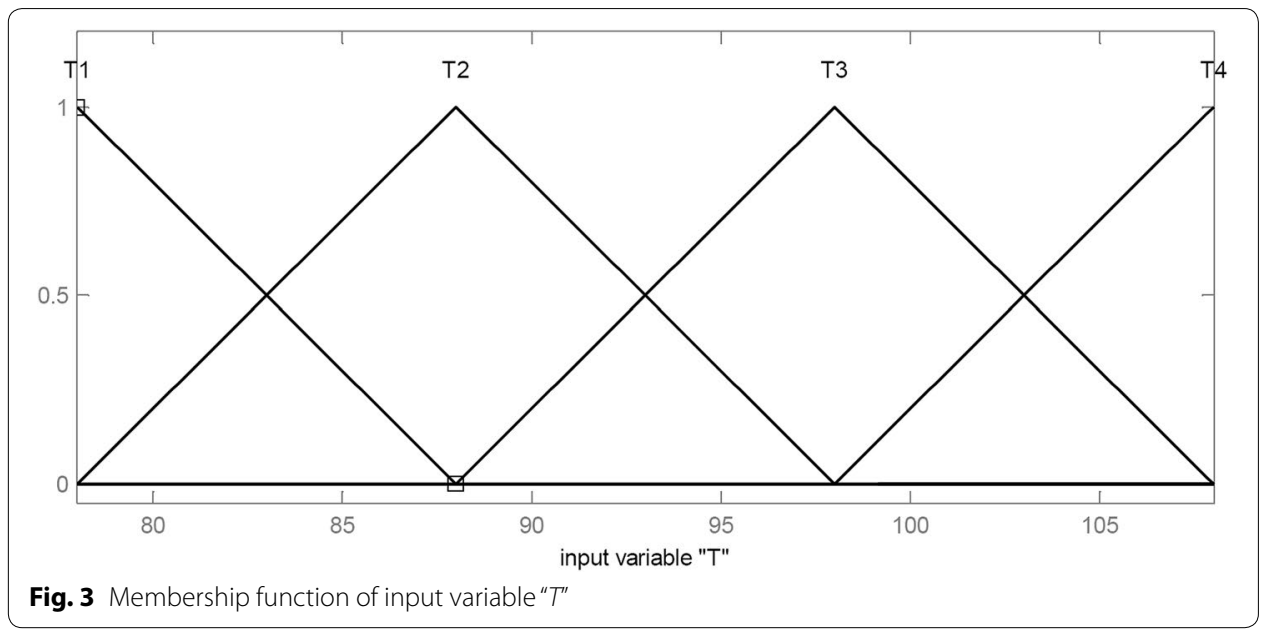

where, $b_{i}$ is the position of the singleton in the $i$ th universe and $\mu_{\mathrm{i}}$ is equal to the membership function of rule $i$.

The schematic diagram of the modeling is shown in Fig. 6.

\section{Prediction performance analysis}

The prediction performance of the developed model was analyzed by root-mean square $(R M S)$, mean absolute error percentage $(M A E P)$ and coefficient of determination $\left(R^{2}\right)$.

The formulation of $R M S, M A E P$ and $R^{2}$ are given below. 


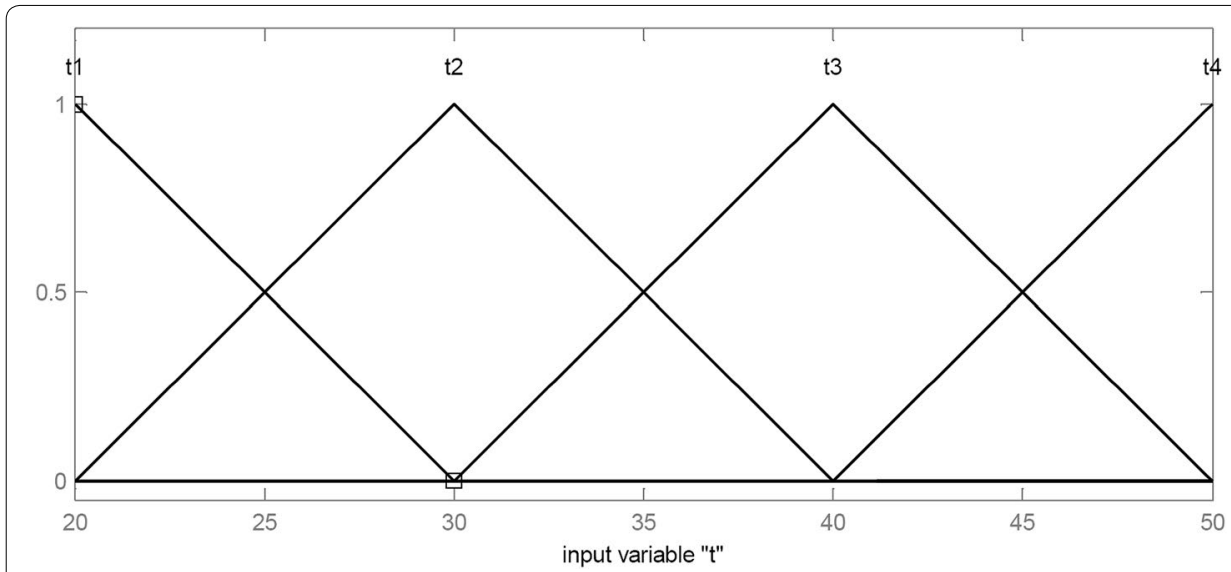

Fig. 4 Membership function of input variable " $t$ "

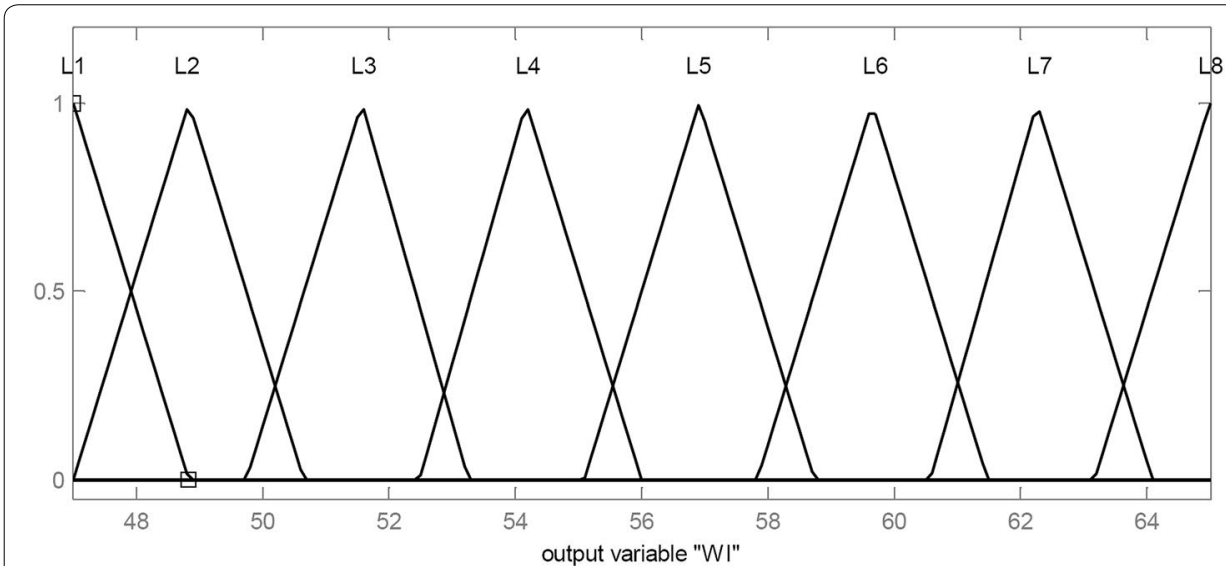

Fig. 5 Membership function of input variable "Wl"

$$
\begin{aligned}
& R^{2}=1-\left(\frac{\sum_{i=1}^{i=N}\left(E_{a}-E_{p}\right)^{2}}{\sum_{i=1}^{i=N}\left(E_{a}-E_{M}\right)^{2}}\right) \\
& R M S=\sqrt{\frac{\sum_{i=1}^{i=N}\left(E_{a}-E_{p}\right)^{2}}{N}} \\
& M A E P=\frac{1}{N} \sum_{i=1}^{i=N}\left(\frac{\left|E_{a}-E_{p}\right|}{E_{a}} \times 100\right)
\end{aligned}
$$

where, $E_{\mathrm{a}}$ is actual result, $E_{\mathrm{p}}$ is predicted result, $E_{\mathrm{m}}$ is mean value and $N$ represents number of pattern.

The coefficient of determination $\left(R^{2}\right)$ is expected to compare the accuracy of a given model with the accuracy of a trivial benchmark model whereas $R M S$ becomes small as close as zero for good accuracy of prediction. The MAEP shows the deviation between 


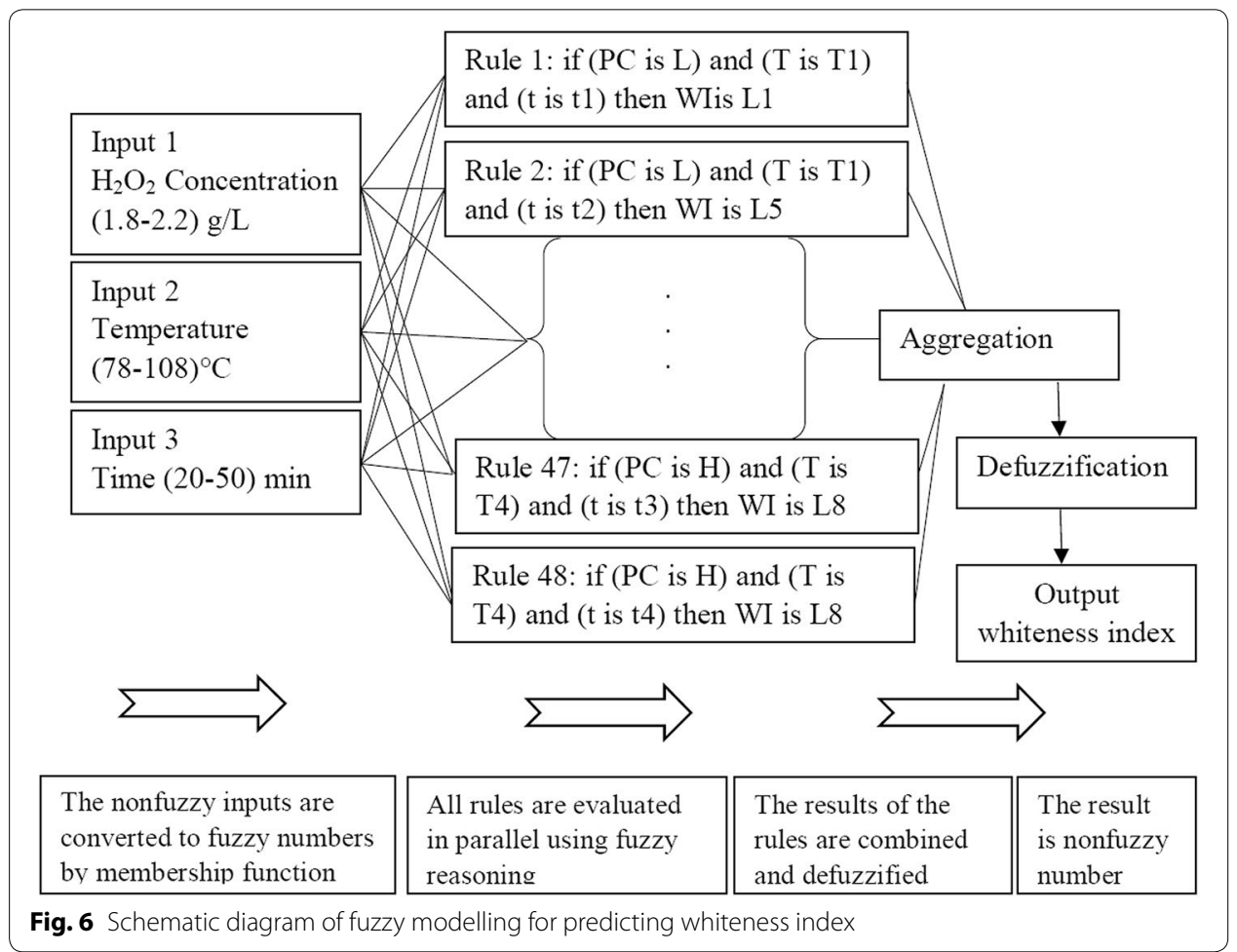

the predicted and investigational values and it is required to reach zero for the best accuracy.

\section{Results and discussion}

\section{Operation of fuzzy prediction model}

An example of the graphical operation of fuzzy logic model is shown in Fig. 7. Only one fuzzy rule (Rule 22) out of 48 is shown in the image for simplicity. According to rule 22 , when hydrogen peroxide concentration is medium $(M)$, Temperature is $T 2$ and Time for bleaching is $t 2$, whiteness index is $L 6$. For instance, if $P C$ is $2 \mathrm{~g} / \mathrm{L}, T$ is $88^{\circ} \mathrm{C}$ and $t$ is $30 \mathrm{~min}$, all 48 fuzzy rules are reviewed simultaneously to get the fuzzy output whiteness index $(W I)$. After aggregation and defuzzification, the ultimate crisp output whiteness index of the fuzzy set is found to be 59.7.

\section{Influence of input variables on whiteness index}

The fuzzy control surfaces were developed Using MATLAB as displayed in Figs. 8, 9 and 10 . The images show the relations between hydrogen peroxide concentrations $(P C)$, temperature $(T)$ and time $(t)$ on the input part and whiteness index $(W I)$ on the output part. The surface plots revealed in Figs. 8, 9 and 10 show the influence of $P C, T$ and $t$ on $W I$.

Figure 8 represents that $W I$ increases with the increase of $P C$ and $T$ and vice versa. Temperature has a steady influence on whiteness index which is enhanced further by peroxide concentration. However the individual effect of peroxide concentration on whiteness index is pretty low and no change in whiteness is found at higher concentrations if temperature remains constant. In fact, WI increases around $2.20 \%$ only for about $22 \%$ increase of $P C$. On the other hand, WI increases near about $25.33 \%$ for around 


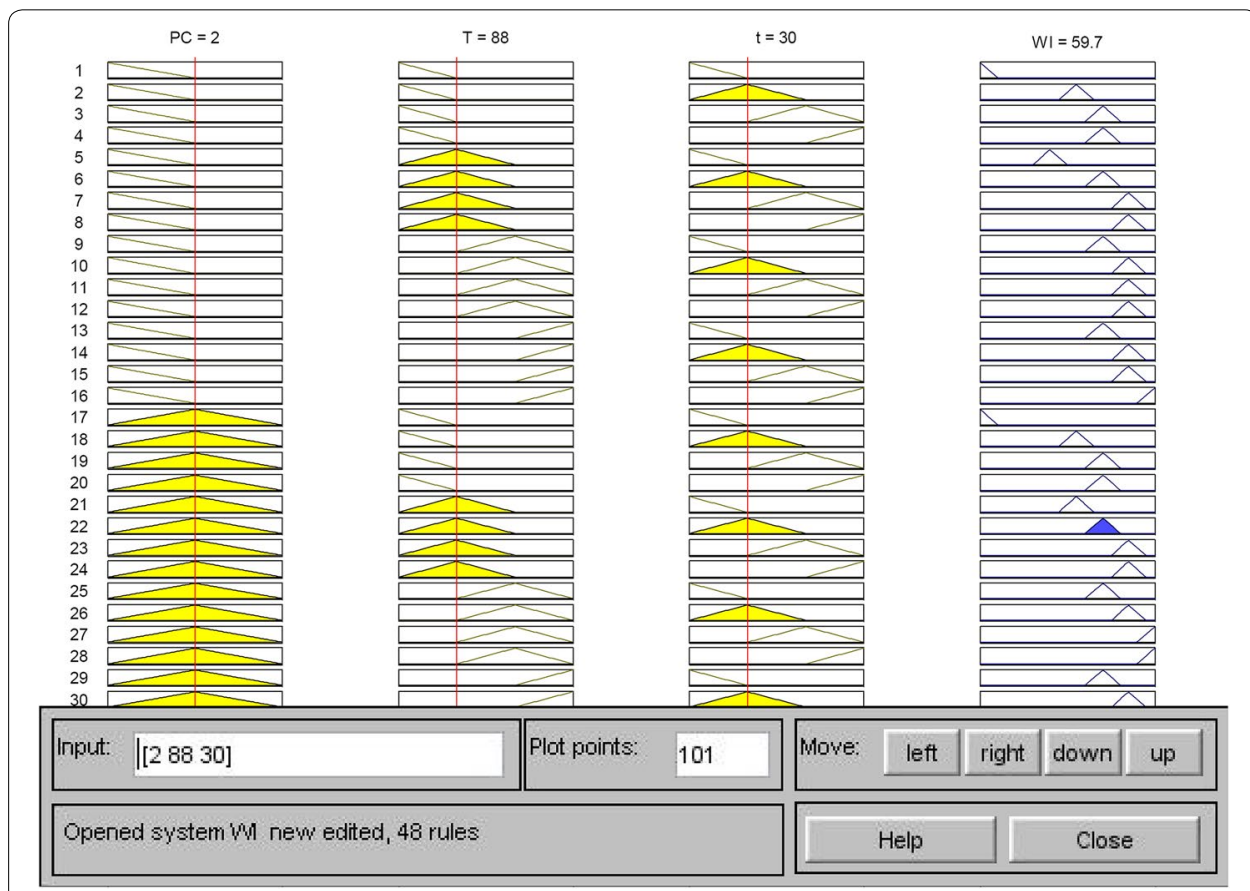

Fig. 7 Graphical operation of fuzzy logic model

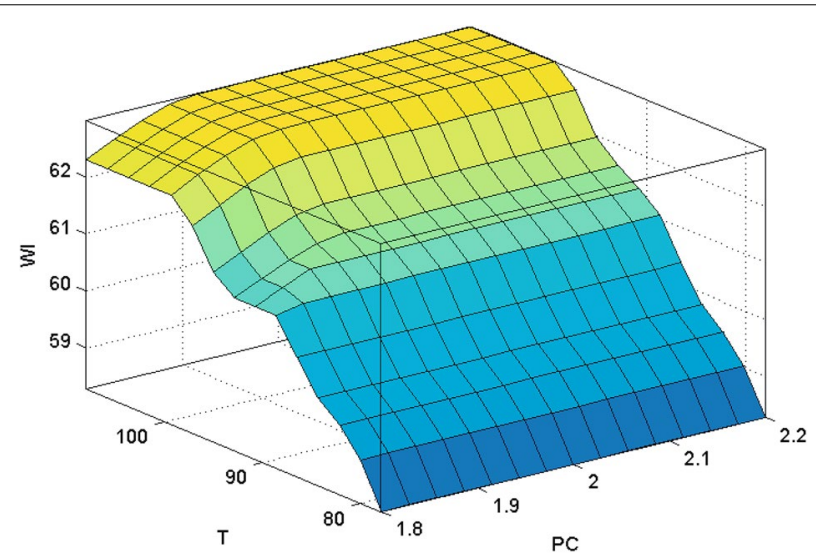

Fig. 8 Surface plot showing the effect of $P C$ and $T$ on $W I$

$38.46 \%$ rise of $T$. It indicates that the whiteness index is affected by temperature significantly even in a fixed concentration of hydrogen peroxide.

A similar phenomenon is observed from Fig. 9 for $t$ and $P C$ on WI. The figure shows that WI increases progressively with the increase of $t$. The effect of $P C$ on WI is found very little here again. Lastly, from Fig. 10, it is observed that both $T$ and $t$ have almost similar influence on WI. Whiteness index increases smoothly with the increase of temperature and time. The rate of increase is initially sharp but slows down later on. For instance, $W I$ increases around $17.65 \%$ for raising temperature from 78 to $88{ }^{\circ} \mathrm{C}$, but it increases only about $6.12 \%$ for raising temperature from 88 to $108{ }^{\circ} \mathrm{C}$. Similarly $W I$ increases around $19.95 \%$ for increasing time from 20 to $30 \mathrm{~min}$, but it increases only 


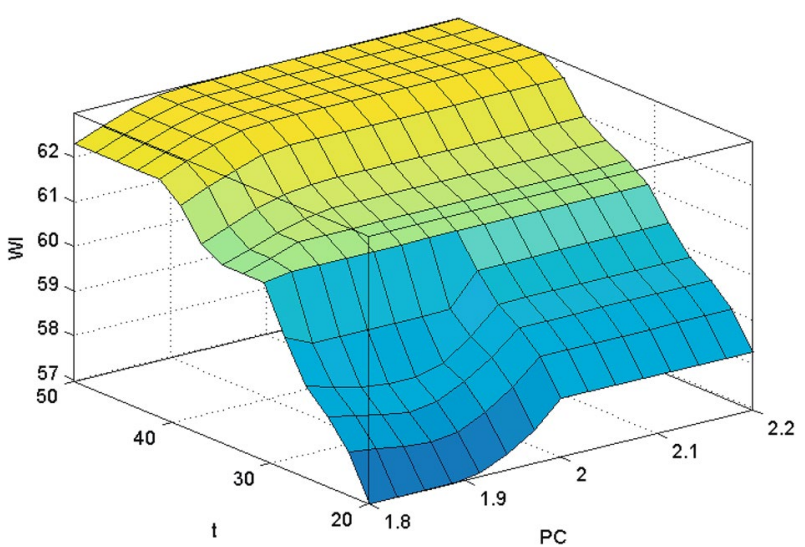

Fig. 9 Surface plot showing the effect of $P C$ and $t$ on $W I$

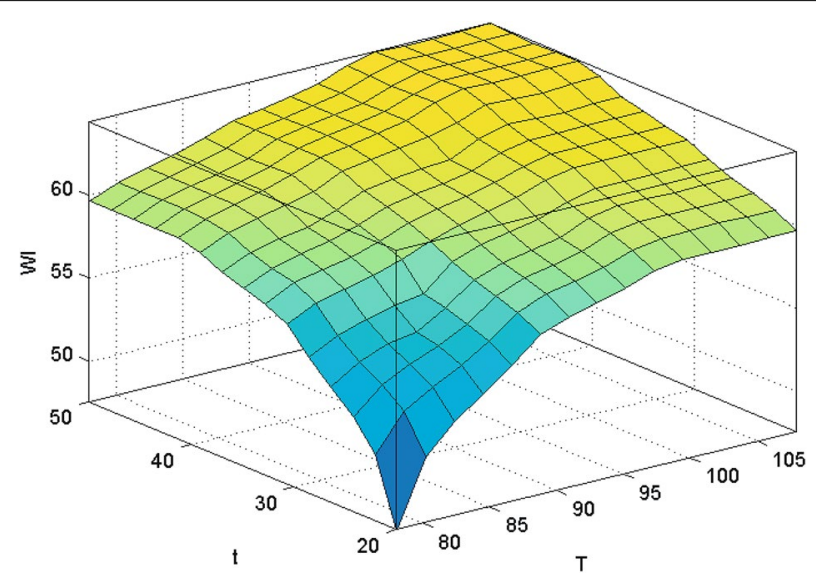

Fig. 10 Surface plot showing the effect of $t$ and $T$ on $W I$

about $4.83 \%$ for increasing time from 30 to $50 \mathrm{~min}$. The influence of $t$ in higher $T$ and influence of $T$ in greater $t$ are found very low in fact (about 4.28\% increase of WI from 20 to $50 \mathrm{~min}$ in $108^{\circ} \mathrm{C}$ and about $7.36 \%$ increase of $W I$ from 78 to $108{ }^{\circ} \mathrm{C}$ in $50 \mathrm{~min}$ ).

Hence, it can be concluded that though hydrogen peroxide is the main element for bleaching operation, temperature of the bleaching bath has a very important positive influence on whiteness index which can be improved by increasing time duration.

\section{Validation and comparison of fuzzy model}

The developed fuzzy prediction model was validated by some new investigational data. 16 fabric samples were bleached again in random parameters and considered to validate the fuzzy model. The correlation between the actual whiteness index and that predicted by the fuzzy logic model are illustrated in Fig. 11. The root-mean squared (RMS), mean absolute error percentage $(M A E P)$ and coefficient of determination $\left(R^{2}\right)$ between the predicted and experimental values of whiteness index of cotton knitted fabric were 


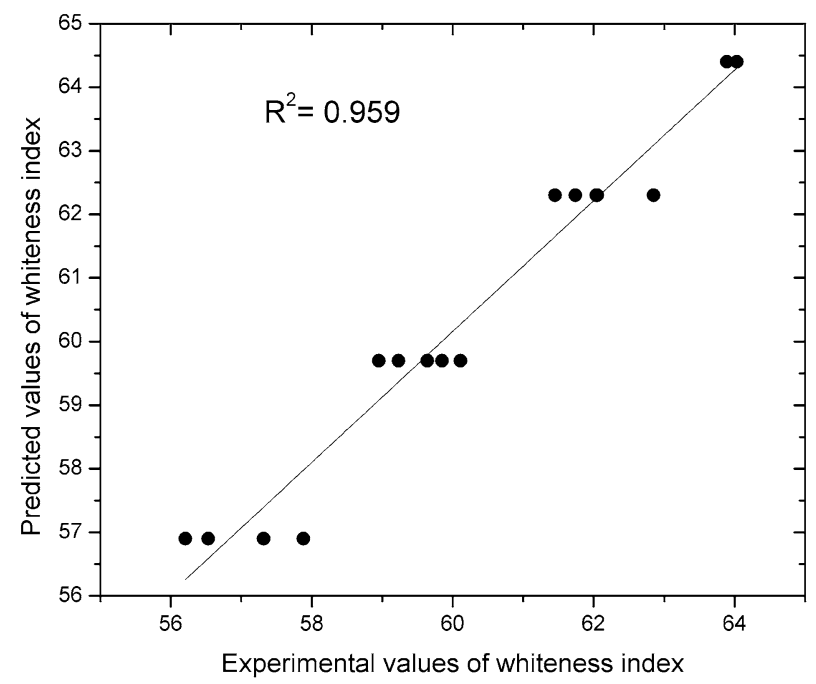

Fig. 11 Correlation between actual and predicted values of whiteness index

found to be $0.536,0.798$ and 0.959 respectively, which evident the close conformity of the developed model. The results are depicted in Table 3.

\section{Conclusions}

In the current study, a fuzzy model has been developed for the prediction of the whiteness index of single jersey cotton knitted fabric. The model was generated by taking three bleaching process parameters $\left(\mathrm{H}_{2} \mathrm{O}_{2}\right.$ concentration, temperature and time) as the input variables and fabric whiteness index as the output variable. The model developed

Table 3 Prediction performance of fuzzy model

\begin{tabular}{llrllll}
\hline SI no. & $\boldsymbol{P C}(\mathbf{g} / \mathbf{L})$ & $\boldsymbol{T}\left({ }^{\circ} \mathbf{C}\right)$ & $\boldsymbol{t}(\mathbf{m i n})$ & Actual $\boldsymbol{W I}$ & Predicted $\boldsymbol{W I}$ & Absolute error \% \\
\hline 1 & 1.8 & 78 & 30 & 56.53 & 56.9 & 0.65452 \\
2 & 1.8 & 88 & 30 & 59.23 & 59.7 & 0.793517 \\
3 & 1.8 & 88 & 50 & 61.74 & 62.3 & 0.907029 \\
4 & 1.8 & 98 & 30 & 61.45 & 62.3 & 1.383238 \\
5 & 1.8 & 98 & 40 & 62.85 & 62.3 & 0.875099 \\
6 & 1.8 & 108 & 20 & 58.95 & 59.7 & 1.272265 \\
7 & 1.8 & 108 & 30 & 62.05 & 62.3 & 0.402901 \\
8 & 2 & 78 & 50 & 59.64 & 59.7 & 0.100604 \\
9 & 2 & 88 & 20 & 56.21 & 56.9 & 1.22754 \\
10 & 2 & 88 & 30 & 60.11 & 59.7 & 0.682083 \\
11 & 2 & 88 & 50 & 62.04 & 62.3 & 0.419084 \\
12 & 2 & 108 & 20 & 59.85 & 59.7 & 0.250627 \\
13 & 2.2 & 78 & 30 & 57.88 & 56.9 & 1.693158 \\
14 & 2.2 & 88 & 20 & 57.32 & 56.9 & 0.732729 \\
15 & 2.2 & 98 & 40 & 63.89 & 64.4 & 0.798247 \\
16 & 2.2 & 98 & 50 & 64.03 & 64.4 & 0.577854 \\
$R^{2}$ & & & & & 0.959 & \\
MAEP & & & & & 0.798 & \\
$R M S$ & & & & & 0.536 & \\
\hline
\end{tabular}


presents an outstanding perceptive on the interaction between bleaching process variables and their effects on whiteness index. It was found that though hydrogen peroxide despite of being the key element for bleaching, the other variables- temperature and time has greater influence on whiteness index. The fuzzy model derived in this study was validated by new investigational data. The root-mean squared $(R M S)$, mean absolute error percentage (MAEP) and coefficient of determination $\left(R^{2}\right)$ between the predicted and experimental values of whiteness index were found to be $0.536,0.798$ and 0.959 respectively. The results exhibit a brilliant prediction performance of the developed fuzzy model. The model will highly suit textile industries for predicting the whiteness index of cotton knitted fabric as a decision making support tool.

\section{Authors' contributions}

MAI, NF and FS did the experimental part of the project. SAS produced the Fuzzy model and ANMAH conducted the interpretation and analysis. The whole project was closely overseen by $\mathrm{MH}$. All authors read and approved the final manuscript.

\section{Author details}

${ }^{1}$ Department of Textile Engineering, Daffodil International University, Dhaka, Bangladesh. ${ }^{2}$ Department of Chemical Engineering, Hanyang University Erica Campus, Ansan, South Korea. ${ }^{3}$ Department of Textile Engineering, Mawlana Bhashani Science and Technology University, Tangail, Bangladesh.

\section{Competing interests}

The authors declare that they have no competing interests.

\section{Ethics approval and consent to participate}

Not applicable.

\section{Publisher's Note}

Springer Nature remains neutral with regard to jurisdictional claims in published maps and institutional affiliations.

Received: 27 August 2017 Accepted: 26 October 2017

Published online: 28 February 2018

\section{References}

Abdel-Halim, E. S. (2012). Simple and economic bleaching process for cotton fabric. Carbohydrate Polymers, 88 , $1233-1238$.

Abdul, S. B., \& Narendra, G. (2013). Accelerated bleaching of cotton material with hydrogen peroxide. Journal of Textile Science \& Engineering, 3(4), 1000140.

Akgun, M. (2015). Effect of fabric layers on whiteness and yellowness indices of some polyester fabrics woven with different constructional parameters. Autex Research Journal, 15, 116-122.

Choudhury, K. R. (2000). Modern concepts of color and appearance. Enfield: Science Publishers Inc.

Choudhury, K. R. (2006). Textile preparation and dyeing. New York: Science Publishers.

Ganz, E. (1979). Whiteness formulas: A selection. Applied Optics, 18, 1073-1078.

Gopal, M. (2010). Digital control and state variable methods: Conventional and intelligent control systems. Singapore: Tata McGraw-Hill Education.

Haghighat, E., Najar, S. S., \& Etrati, S. M. (2014). The prediction of needle penetration force in woven denim fabrics using soft computing models. Journal of Engineered Fibers and Fabrics, 9, 45-55.

Haque, A. N. M. A., \& Islam, M. A. (2015). Optimization of bleaching parameters by whiteness index and bursting strength of knitted cotton fabric. IJSTR, 4(4), 40-43.

Hatua, P., Majumdar, A., \& Das, A. (2014). Modelling ultraviolet protection factor of polyester-cotton blended woven fabrics using soft computing approaches. Journal of Engineered Fibers and Fabrics, 9, 99-106.

Hossain, I., Choudhury, I. A., Mamat, A. B., \& Hossain, A. (2017). Journal of the Textile Institute. https://doi.org/10.1080/00405 000.2017 .1279004$.

Hossain, I., Choudhury, I. A., Mamat, A. B., Shahid, A., Khan, A. N., \& Hossain, A. (2016). Predicting the mechanical properties of viscose/lycra knitted fabrics using fuzzy technique. Advances in Fuzzy Systems, 2016, 1-9.

Hossain, I., Hossain, A., \& Choudhury, I. A. (2015). Color strength modeling of viscose/lycra blended fabrics using a fuzzy logic approach. Journal of Engineered Fibers and Fabrics, 10, 158-168.

Hossain, I., Hossain, A., Choudhury, I. A., Bakar, A. \& Uddin, H. (2014). Prediction of fabric properties of viscose blended knitted fabrics by fuzzy logic methodology. In International conference on mechanical and civil and architectural engineering, 19-20 February 2014, Kuala Lumpur, Malaysia, pp.100-106.

Jafari, R., \& Amirshahi, S. H. (2007). A comparison of the CIE and UCHIDA whiteness formulae as predictor of average visual whiteness evaluation of textiles. Textile Research Journal, 77, 756-763. 
Jafari, R., \& Amirshahi, S. H. (2008). Variation in the decisions of observers regarding the ordering of white samples. Coloration Technology, 124, 124-131.

Jamshaid, H., Hussain, T., \& Malik, Z. A. (2013). Comparison of regression and adaptive neuro-fuzzy models for predicting the bursting strength of plain knitted fabrics. Fibers and Polymers, 14, 1203-1207.

Jeguirim, S. E. G., Dhouib, A. B., Sahnoun, M., Cheikhrouhou, M., Schacher, L., \& Adolphe, D. (2011). The use of fuzzy logic and neural networks models for sensory properties prediction from process and structure parameters of knitted fabrics. Journal of Intelligent Manufacturing, 22, 873-884.

Kabir, S. M. F., Iqbal, M. I., Sikdar, P. P., Rahman, M. M., \& Akhter, S. (2014). Optimization of parameters of cotton fabric whiteness. ESJ, 10(36), 200-210.

Majumdar, A., \& Ghosh, A. (2008). Yarn strength modeling using fuzzy expert system. Journal of Engineered Fibers and Fabrics, 3, 61-68.

Marakoğlu, T., \& Çarman, K. (2010). Fuzzy knowledge-based model for prediction of soil loosening and draft efficiency in tillage. Journal of Terramechanics, 47, 173-178.

Ngai, E. W. T., Peng, S., Alexander, P., \& Moon, K. K. (2014). Decision support and intelligent systems in the textile and apparel supply chain: An academic review of research articles. Expert Systems with Applications, 41, 81-91.

Shahid, A., \& Hossain, I. (2015). Modeling the spirality of cotton knit fabric using fuzzy expert system. Turkish Journal of Fuzzy Systems, 6, 56-67.

Steen, D., \& Dupont, D. (2003). Control of structured white textiles. Coloration Technology, 119, 205-211.

Trotman, E. R. (1975). Dyeing and chemical technology of textile fibres. Bucks: Charles Griffin \& CO. Ltd.

Uchida, H. (1998). A new whiteness formula, color research and application. Color Research and Application, 23, 202-209.

Vadood, M. (2014). Predicting the color index of acrylic fiber using fuzzy genetic approach. The Journal of The Textile Institute, 105, 779-788.

Vigneswaran, A., Ananthasubramanian, M., \& Anbumani, N. (2012). Prediction and process optimization of bioscouring of organic cotton fabrics through specific mixed enzymatic system using artificial neural network (ANN). Journal of Natural Fibers, 9, 1-22.

Wyszecki, G., \& Stiles, W. S. (1982). Color science: Concepts and methods, quantitative data and formulae. New York: John Wiley.

Zadeh, L. A. (1965). Fuzzy sets. Information and Control, 8, 338-353.

Zollinger, H. (2003). Color chemistry, syntheses, properties, and applications of organic dyes and pigments. New York: Wiley-VCH.

\section{Submit your manuscript to a SpringerOpen ${ }^{\circ}$ journal and benefit from:}

- Convenient online submission

- Rigorous peer review

- Open access: articles freely available online

- High visibility within the field

Retaining the copyright to your article

Submit your next manuscript at $\mathbf{s p r i n g e r o p e n . c o m ~}$ 